\title{
Corrosion Inhibition of Cu-Zn-Fe Alloy in Hydrochloric Acid Medium by Crude Ethanol Extracts from Roots-Leaves Synergy of Solanum melongena
}

\author{
Benedict U. Ugi \\ Department of Pure \& Applied Chemistry, University of Calabar, P.M.B. 1115 Calabar, Nigeria \\ e-mail: ugibenedict@gmail.com
}

\begin{abstract}
The corrosion inhibition of $\mathrm{Cu}-\mathrm{Zn}-\mathrm{Fe}$ alloy in hydrochloric acid medium by crude ethanol extracts from roots-leaves synergy of Solanum melongena have been studied with chemical methods (mass loss and gasometric methods). At 3.0 grams per litre concentration of the roots-leaves synergy of Solanum melongena, it was observed that a $98.8 \%$ inhibition efficiency was recorded as corrosion rate of alloy was decreasing with inhibitor increase. Temperature evaluation on the inhibitor showed $99.2>88.4>85.6 \%$ as trial was conducted from 303-323 respectively, and in respect to increasing concentration, corrosion rate was found to be $1.718>0.013,0.0192$ and 0.247 at 303, 313 and 323 respectively. All these present a good result for the synergistic inhibitor and a proof of its efficiency in controlling the corrosion of $\mathrm{Cu}-\mathrm{Zn}-\mathrm{Fe}$ alloy in hydrochloric acid medium. Inhibition mechanism was deduced from the activation and thermodynamic parameters that govern the process. Adsorption of extract on the $\mathrm{Cu}-\mathrm{Zn}-\mathrm{Fe}$ alloy was found to obey the Langmuir adsorption isotherm. The phenomenon of physical adsorption is proposed from the obtained thermodynamic parameters.
\end{abstract}

\section{Introduction}

Corrosion is a natural process since all natural processes tend toward the lowest possible energy states [1-3]. The most common kinds of corrosion result from electrochemical reactions. General corrosion occurs when most or all of the atoms on the same metal surface are oxidized, damaging the entire surface. Most metals are easily

Received: October 26, 2020; Accepted: November 24, 2020

Keywords and phrases: adsorption, inhibition, corrosion, Solanum melongena, $\mathrm{Cu}-\mathrm{Zn}-\mathrm{Fe}$ alloy, ethanol.

Copyright (C) 2021 Benedict U. Ugi. This is an open access article distributed under the Creative Commons Attribution License, which permits unrestricted use, distribution, and reproduction in any medium, provided the original work is properly cited. 
oxidized: they tend to lose electrons to oxygen (and other substances) in the air or in water. The effects of corrosion in our daily lives are both direct, in that corrosion affects the useful service lives of our possessions, and indirect, in that producers and suppliers of goods and services incur corrosion costs, which they pass unto the consumers [2-5]. Some of the effects of corrosion include a significant deterioration of natural and historic monuments as well as increase the risk of catastrophic equipment failures. Corrosion also degrades important infrastructure such as steel-reinforced-highways, electrical towers, parking structures and bridges [4, 5-7]. Its effects can also be seen in plant shutdown, waste of valuable resources, loss or contamination of products, reduction in efficiency, and expensive overdesign. Corrosion damage can be prevented by using various methods such as upgrading materials, blending of production fluids, process control and chemical inhibition [2, 5-7]. The known effects of most synthetic corrosion inhibitors are the motivation for the use of some natural products. Natural products are nontoxic, biodegradable and readily available. Green and eco-friendly inhibitor research have become a wide spread area of corrosion control especially due to their environmental friendly, less expensive and easy availability and accessibility nature [1-3, 7-10]. Their effective and wide spread interest is also centered on the presence of hetero-atoms and dominance of aromatic characteristics, and alkyl groups that act to reduce corrosion through adsorption on metal and alloy surfaces the plant extracts are considered as an incredibly rich source of environmentally acceptable corrosion inhibitors [8-11]. This work is aimed at investigating Corrosion inhibition of $\mathrm{Cu}-\mathrm{Zn}-\mathrm{Fe}$ alloy in hydrochloric acid medium by crude ethanol extracts from roots-leaves synergy of Solanum melongena

\section{Experimental}

\subsection{Preparation of ethanol extracts of Solanum melongena}

The required roots and leaves of Solanum melongena were dried separately in a laboratory oven at a minimal temperature to avoid loss of major organic components of the plant and ground into powder form. Each powdered sample was extracted continually with absolute ethanol in a Soxhlet extractor for 48 hours. The extracts obtained separately were later evaporated of the excess ethanol through a water bath at $60^{\circ} \mathrm{C}$. Ten grams each of the ethanol extracts of leaf and root were weighed and together diluted with $1000 \mathrm{ml} 1$ $\mathrm{M} \mathrm{HCl}$ solution then kept for 24 hours to allow for complete dissolution. From the stock solution $(10 \mathrm{~g} / \mathrm{L})$, inhibitor test solutions were prepared to obtain $1.0 \mathrm{~g} / \mathrm{L}, 1.5 \mathrm{~g} / \mathrm{L}, 2.0$ $\mathrm{g} / \mathrm{L}, 2.5 \mathrm{~g} / \mathrm{L}$ and $3.0 \mathrm{~g} / \mathrm{L}$ for mass loss and gasometric measurements respectively. The prepared solutions were then used to study the corrosion inhibition abilities of the extract. 


\subsection{Mass loss measurements}

Prepared and weighed $5.0 \mathrm{~cm} \times 0.08 \mathrm{~cm} \mathrm{Cu}-\mathrm{Zn}-\mathrm{Fe}$ alloy dimension were considered for the mass loss experiment. These metals were immersed in various concentrations including the blank solution of the synergistic inhibitor using a $100 \mathrm{ml}$ beaker and suspended with a polythene rope and a glass rod. Each of the test specimens were removed daily from the test solution, washed with distilled water, rinsed with ethanol, dried with acetone and re-weighed. Plots of weight loss against exposure time and concentration were generated and corrosion rates obtained from plots. Surface coverage and inhibition efficiency were estimated from equations (1) and (2) respectively:

$$
\begin{aligned}
& \theta=1-\frac{W_{1}}{W_{2}} \\
& \mathrm{IE} \%=\theta \times 100
\end{aligned}
$$

where $\theta$ is the surface coverage, $W_{1}$ is the corrosion rate of the blank, $W_{2}$ is the corrosion rate of the inhibitor, IE\% is the inhibition efficiency.

\subsection{Hydrogen evolution measurements}

$100 \mathrm{~mL}$ of the $1 \mathrm{M} \mathrm{HCl}$ was introduced into the assembly and the initial volume of the indicator was noted. This was followed with the prepared and weighed $1.20 \mathrm{~cm} \times 0.08$ $\mathrm{cm} \times 4.00 \mathrm{~cm} \mathrm{Cu}-\mathrm{Zn}-\mathrm{Fe}$ alloy dimension dropped into the blank solution $(1 \mathrm{M} \mathrm{HCl})$ and the flask quickly closed. The volume of the hydrogen gas evolved from the corrosion reaction was monitored by volume changes in assembly after every minute for 30 minutes. In another experiment, a set of fresh alloy were immersed in the flask containing the inhibitor solutions $(1.0 \mathrm{~g} / \mathrm{L}, 1.5 \mathrm{~g} / \mathrm{L}, 2.0 \mathrm{~g} / \mathrm{L}, 2.5 \mathrm{~g} / \mathrm{L}$ and $3.0 \mathrm{~g} / \mathrm{L})$ and the experiment repeated again. The study was conducted at $303 \mathrm{~K}, 313$ and $323 \mathrm{~K}$ using a thermostat water bath.

\section{Results and Discussion}

\subsection{Effects of inhibitor concentration on mass loss of Cu-Zn-Fe alloy}

Mass loss of metal or alloy is a consequence of the corrosion rate of the alloy due to oxidation at the anodic sites and cathodic hydrogen evolution $[6,9,11]$. The $\mathrm{Cu}-\mathrm{Zn}-\mathrm{Fe}$ alloy was found from Figures 1 and 2 to experience a increase in mass loss with increase in immersion time which could be as a result of increase retention of dissolved alloy particles which serves as bulk impurities [10-13]. The same mass loss was found decreasing with increase concentration implying that the corrosion sites in the alloy were 
inhibited by the root-leaves synergy extracts [11-15]. This has been confirmed from Table 1 and Figure 3a-b were surface coverage $(\theta)$ and inhibition efficiency (IE\%) of Cu$\mathrm{Zn}-\mathrm{Fe}$ alloy increased with increase in inhibitor concentrations proving that the corrosion of the metal has been inhibited and a larger fraction of the surface is protected against alkaline attack $[13,16]$.

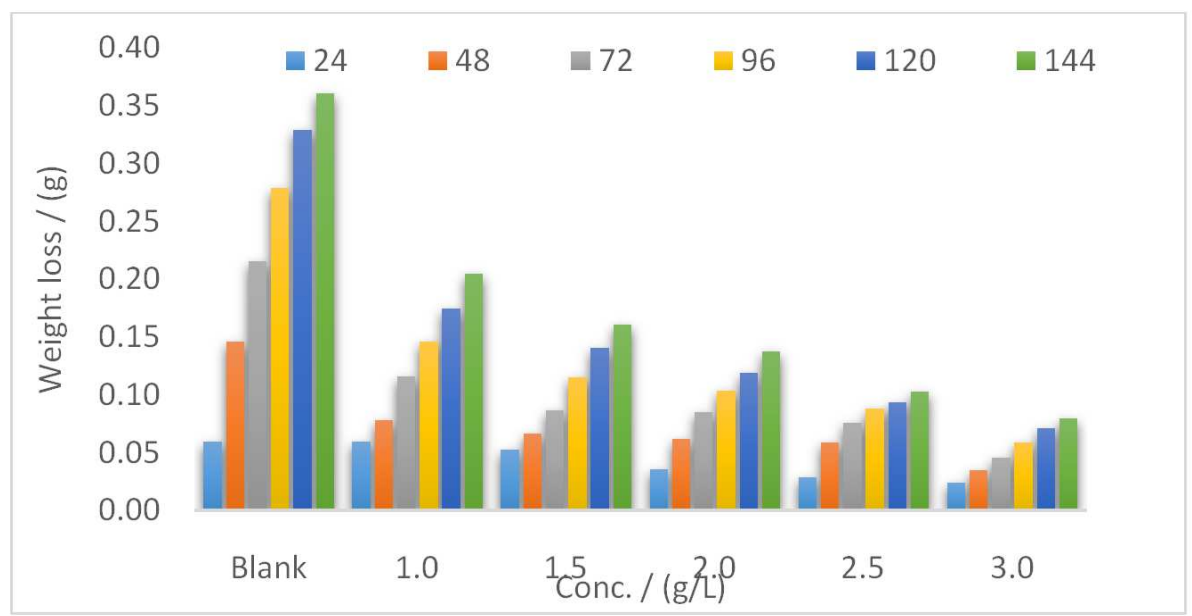

Figure 1. Variation of weight loss with immersion time for $\mathrm{Cu}-\mathrm{Zn}-\mathrm{Fe}$ alloy in the presence and absence of root-leaves synergy extracts of Solanum melongena leaves.

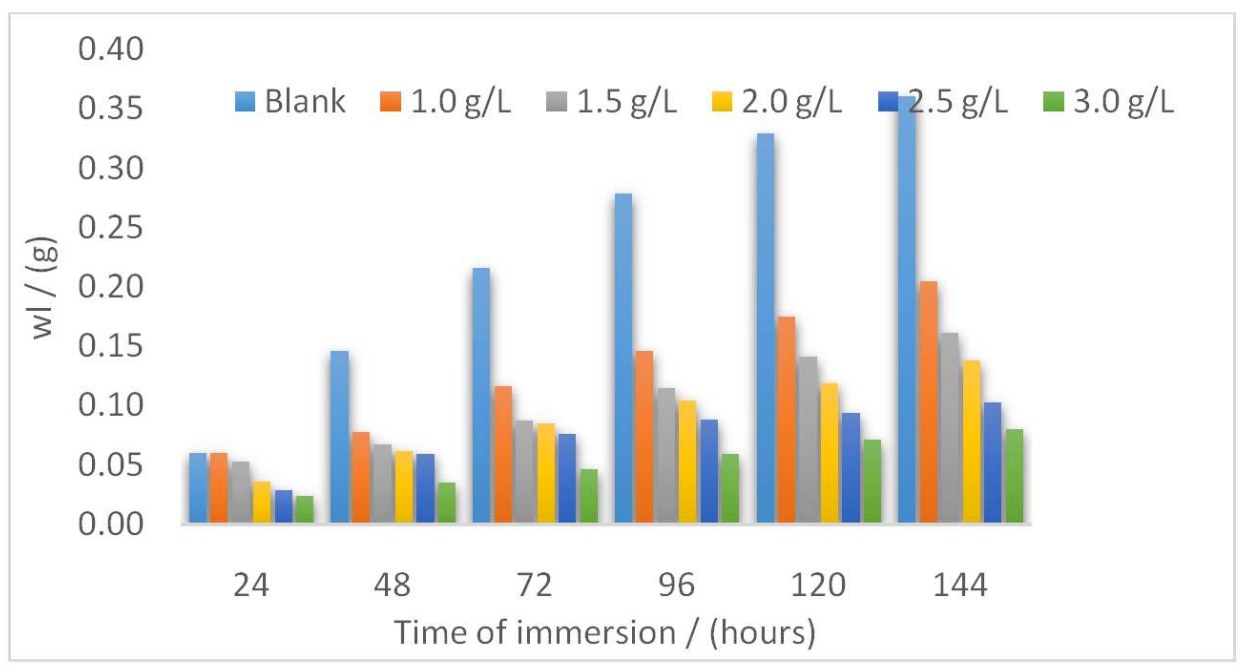

Figure 2. Variation of weight loss with concentration for $\mathrm{Cu}-\mathrm{Zn}-\mathrm{Fe}$ alloy in the presence and absence of root-leaves synergy extracts of Solanum melongena leaves. 
Table 1. Corrosion rates, surface coverage and inhibition efficiency for $\mathrm{Cu}-\mathrm{Zn}-\mathrm{Fe}$ alloy in the presence and absence of root-leaves synergy extracts of Solanum melongena leaves.

\begin{tabular}{cccc}
\hline System & $\mathrm{CR}\left(\mathrm{mg} / \mathrm{cm}^{2} / \mathrm{hr}\right)$ & $\theta$ & IE\% \\
\hline (Blank) & 1.027 & - & - \\
$1.0 \mathrm{~g} / \mathrm{L}$ & 0.237 & 0.769 & 76.9 \\
$1.5 \mathrm{~g} / \mathrm{L}$ & 0.189 & 0.816 & 81.6 \\
$2.0 \mathrm{~g} / \mathrm{L}$ & 0.113 & 0.889 & 88.9 \\
$2.5 \mathrm{~g} / \mathrm{L}$ & 0.096 & 0.907 & 90.7 \\
$3.0 \mathrm{~g} / \mathrm{L}$ & 0.033 & 0.988 & 98.8 \\
\hline
\end{tabular}

$\mathrm{CR}=$ Corrosion rate $\quad \theta=$ Surface Coverage $\quad$ IE $\%=$ Inhibition efficiency

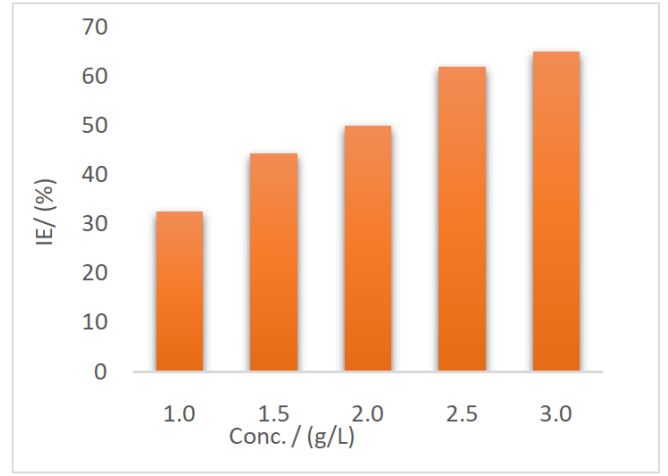

(a)

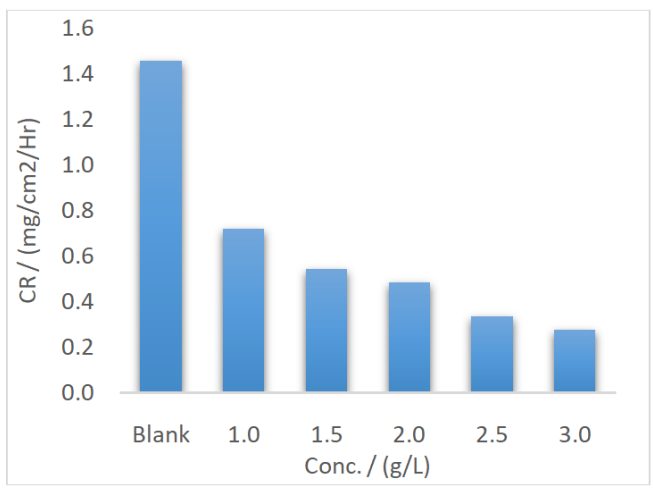

(b)

Figure 3. Variation of (a) $\mathrm{IE}(\%)$ and (b) $\mathrm{CR}$ with Conc. for $\mathrm{Cu}-\mathrm{Zn}-\mathrm{Fe}$ alloy in the presence and absence of root-leaves synergy extracts of Solanum melongena leaves.

\subsection{Effects of temperature on hydrogen gas evolution in $\mathrm{Cu}$-Zn-Fe alloy inhibition}

Table 2 revealed an inhibitor efficiency of $99.2 \%>88.4 \%>85.6 \%$ as test was conducted between 303-323 K respectively, while in respect to increasing concentration, corrosion rate was found to be 1.718 (Blank) > 0.013 (303 K), 0.0192 (313K) and 0.247 (323K). The first scenario informed the gradual desorption of the weakly held inhibitor molecules on the $\mathrm{Cu}-\mathrm{Zn}-\mathrm{Fe}$ alloy surface due to strong increase temperature agitation from 303 to $323 \mathrm{~K}[12,15,16-20]$. This decrease in inhibition efficiency with increase 
temperature reveals a physical adsorption process [11-16]. The decrease in corrosion rate of $\mathrm{Cu}-\mathrm{Zn}-\mathrm{Fe}$ alloy as concentration increases explained the strong adsorption of the inhibitor molecules even at agitated temperatures [20-22] and all these present a good result for the synergistic inhibitor and a proof of its efficiency in controlling the corrosion of $\mathrm{Cu}-\mathrm{Zn}-\mathrm{Fe}$ alloy in hydrochloric acid medium. This has been summarized on the chart in Figures 4a-c.

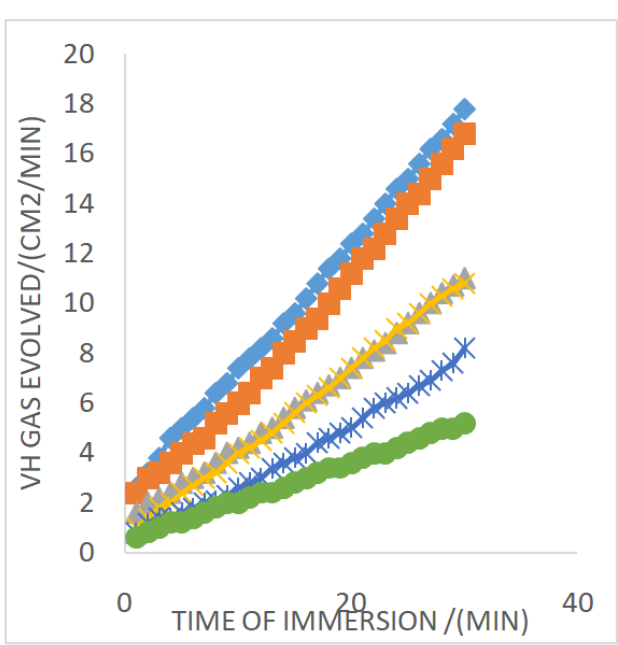

(a)

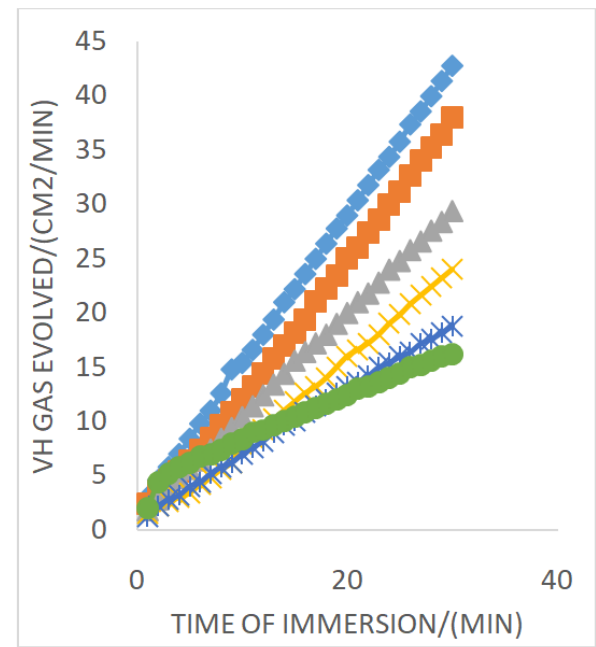

(b)

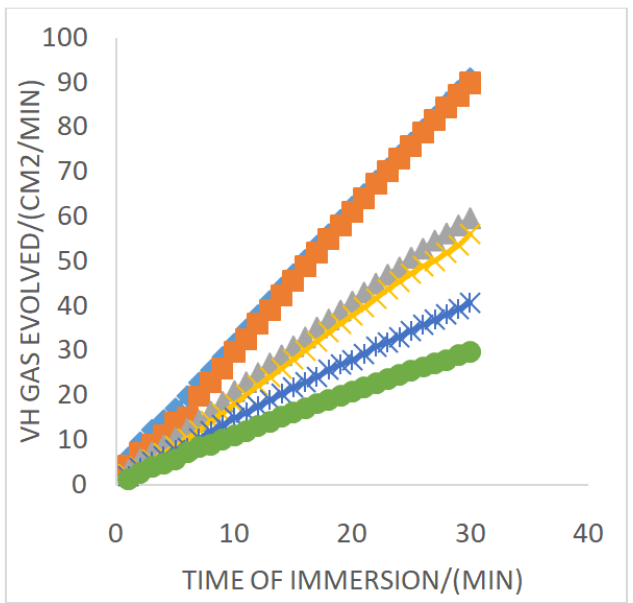

(c)

Figure 4. Variation of weight loss with concentration for $\mathrm{Cu}-\mathrm{Zn}-\mathrm{Fe}$ Alloy in the presence and absence of root-leaves synergy extracts of Solanum melongena leaves. 
Table 2. Corrosion rate, surface coverage and inhibition efficiency for $\mathrm{Cu}-\mathrm{Zn}-\mathrm{Fe}$ alloy in the presence and absence of root-leaves synergy extracts of Solanum melongena leaves.

\begin{tabular}{|c|c|c|c|c|c|c|c|c|c|}
\hline & \multicolumn{3}{|c|}{$303 \mathrm{~K}$} & \multicolumn{3}{|c|}{$313 \mathrm{~K}$} & \multicolumn{3}{|c|}{$323 \mathrm{~K}$} \\
\hline $\begin{array}{l}\text { Inhibitor } \\
\text { Conc. }\end{array}$ & $\begin{array}{c}\mathrm{CR} \\
(\mathrm{mg} / \mathrm{cm} 2 / \mathrm{min})\end{array}$ & $\theta$ & $\begin{array}{l}\mathrm{IE} \\
(\%)\end{array}$ & $\begin{array}{c}\mathrm{CR} \\
(\mathrm{mg} / \mathrm{cm} 2 / \mathrm{min})\end{array}$ & $\theta$ & $\begin{array}{l}\mathrm{IE} \\
(\%)\end{array}$ & $\begin{array}{c}\mathrm{CR} \\
(\mathrm{mg} / \mathrm{cm} 2 / \mathrm{min})\end{array}$ & $\theta$ & $\begin{array}{c}\mathrm{IE} \\
(\%)\end{array}$ \\
\hline Blank & 1.718 & - & - & 1.718 & - & - & 1.718 & - & - \\
\hline $1.0 \mathrm{~g} / \mathrm{L}$ & 0.173 & 0.899 & 89.9 & 0.395 & 0.770 & 77.0 & 0.471 & 0.726 & 72.6 \\
\hline $1.5 \mathrm{~g} / \mathrm{L}$ & 0.099 & 0.942 & 94.2 & 0.375 & 0.782 & 78.2 & 0.471 & 0.770 & 77.0 \\
\hline $2.0 \mathrm{~g} / \mathrm{L}$ & 0.047 & 0.973 & 97.3 & 0.291 & 0.831 & 83.1 & 0.379 & 0.779 & 77.9 \\
\hline $2.5 \mathrm{~g} / \mathrm{L}$ & 0.022 & 0.987 & 98.7 & 0.276 & 0.839 & 83.9 & 0.348 & 0.797 & 79.7 \\
\hline $3.0 \mathrm{~g} / \mathrm{L}$ & 0.013 & 0.992 & 99.2 & 0.192 & 0.884 & 88.4 & 0.247 & 0.856 & 85.6 \\
\hline
\end{tabular}

\subsection{Thermodynamics}

The temperature of the system was varied across the inhibitor concentrations from which the activation energy for the corrosion of $\mathrm{Cu}-\mathrm{Zn}-\mathrm{Fe}$ alloy in $1 \mathrm{M} \mathrm{HCl}$ was evaluated using the Arrhenius equation given by equation 3 .

$$
\ln R_{c}=\ln A-\frac{E_{a}}{R T}
$$

where $R_{c}$ is the corrosion rate, $E_{a}$ is the apparent effective activation energy, $R$ is the general gas constant, and $A$ is the Arrhenius pre-exponential. Calculated values of Activation energy between $303 \mathrm{~K}$ and $323 \mathrm{~K}$ were obtained from the slope of Figure 5 and presented in Table 3. The values obtained in the inhibitor solution are greater than the value for the blank solution indicating that inhibitor retards the corrosion of $\mathrm{Cu}-\mathrm{Zn}-\mathrm{Fe}$ alloy in $1 \mathrm{M} \mathrm{HCl}$ solution [9, 13, 22-24]. Since the activation energy increased with inhibitor concentration, it implies that more energy has to be supplied to the system for the corrosion reaction to take place thus the observed decrease in corrosion rate [14, 22, 24-26]. The values are also consistent with the data expected for the mechanism of physical adsorption $\left(<80 \mathrm{kJmol}^{-1}\right)$ [17-21]. Enthalpy $\left(\Delta H_{a d s}\right)$, Entropy $\left(\Delta S_{a d s}\right)$ and Heat of adsorption $\left(Q_{a d s}\right)$ of Solanum melongena root-leaves extracts on $\mathrm{Cu}-\mathrm{Zn}-\mathrm{Fe}$ alloy were calculated using equations 4 (transition state equation) and 5 (for heat of adsorption equation),

$$
\frac{C R}{T}=\log \frac{R}{N h}+\frac{\Delta S}{2.303 R}-\frac{\Delta H}{2.303 R T} \log
$$




$$
Q_{a d s}=2.303 R \log \frac{\theta_{2}}{1-\theta_{2}}-\log \frac{\theta_{1}}{1-\theta_{1}} \times \frac{T_{1} \times T_{2}}{T_{2}-T_{1}} \quad \mathrm{KJmol}^{-1}
$$

where $Q_{a d s}$ is the heat of adsorption, $R$ is the universal gas constant, $\theta_{1}$ and $\theta_{2}$ are the degrees of surface coverage of the inhibitors at temperatures $T_{1}$ and $T_{2}$ respectively. From equation 4, values of $\log (C R / T)$ were plotted against $1 / T$ as shown in Figure 6 and from the slop and intercept of the plot, values of enthalpy and entropy of adsorption were calculated as shown in Table 3. From the calculated values of $\Delta H^{*}$ (Table 3), it can be deduced that the adsorption of the inhibitor on $\mathrm{Cu}-\mathrm{Zn}-\mathrm{Fe}$ alloy surface is exothermic and the reaction becomes less exothermic with increase in inhibitor concentration [24-28]. The negative values of $Q_{a d s}$ indicated that the degree of surface coverage decrease with rise in temperature, supporting the earlier assumptions of physisorption mechanism for the inhibitor. The negative values for $\Delta S^{*}$ shows the non-spontaneous dissolution of the $\mathrm{Cu}-\mathrm{Zn}-\mathrm{Fe}$ alloy and the increase in its values suggests decrease in disordering in the rate determining step [26-29].

Table 3. Values of activation/thermodynamic parameters for carbon steel in $5 \mathrm{M} \mathrm{Na}_{2} \mathrm{CO}_{3}$ in the absence and presence of the plant extracts

\begin{tabular}{ccccc}
\hline System & Ea $(\mathrm{kJ} / \mathrm{mol})$ & $\Delta H_{\text {ads }}^{*}(\mathrm{~kJ} / \mathrm{mol})$ & $\Delta S_{\text {ads }}^{*}(\mathrm{~kJ} / \mathrm{mol})$ & $Q_{\text {ads }}(\mathrm{kJ} / \mathrm{mol})$ \\
\hline Blank & 6.9 & 66.9 & -76.4 & - \\
$1.0 \mathrm{~g} / \mathrm{L}$ & 10.0 & 74.5 & -62.0 & -36.10 \\
$1.5 \mathrm{~g} / \mathrm{L}$ & 11.8 & 104.7 & -35.9 & -43.21 \\
$2.0 \mathrm{~g} / \mathrm{L}$ & 11.8 & 104.7 & -27.9 & -44.14 \\
$2.5 \mathrm{~g} / \mathrm{L}$ & 12.1 & 123.8 & -24.1 & -55.80 \\
$3.0 \mathrm{~g} / \mathrm{L}$ & 14.1 & 131.3 & -21.4 & -72.65 \\
\hline
\end{tabular}




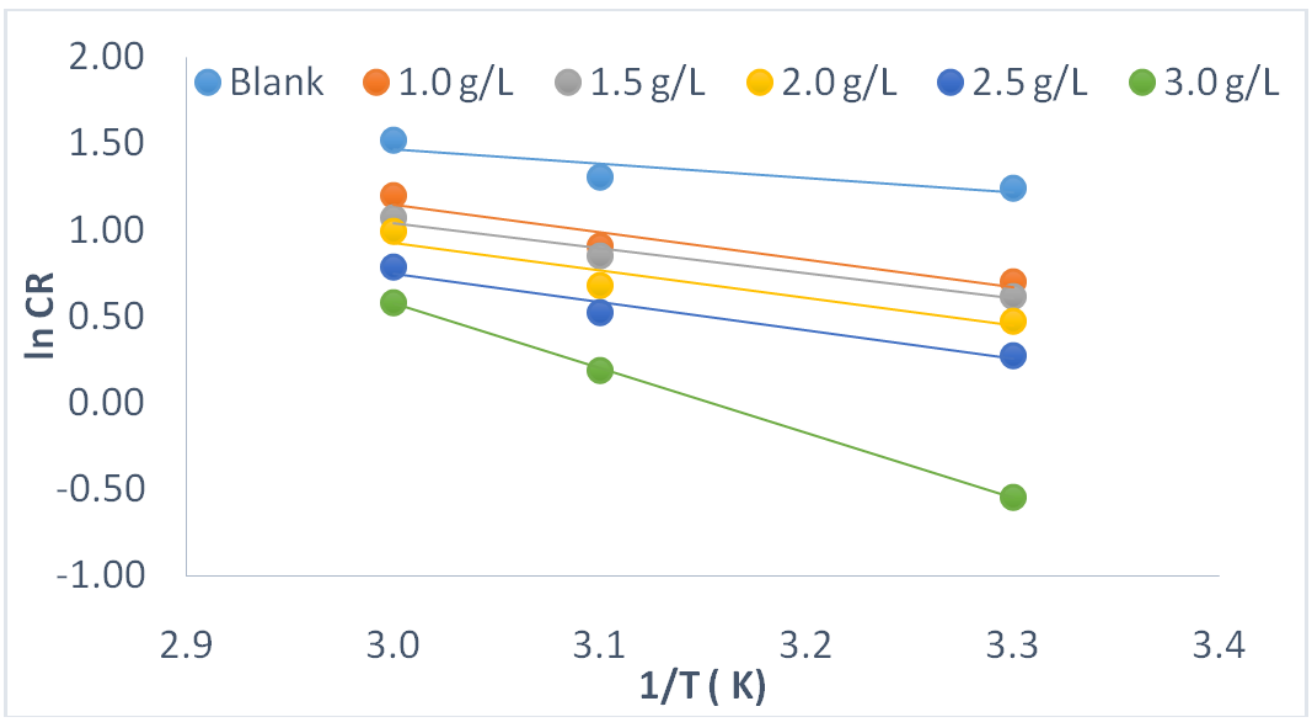

Figure 5. Arrhenius plots for corrosion of $\mathrm{Cu}-\mathrm{Zn}-\mathrm{Fe}$ alloy in the presence and absence of root-leaves synergy extracts of Solanum melongena leaves.

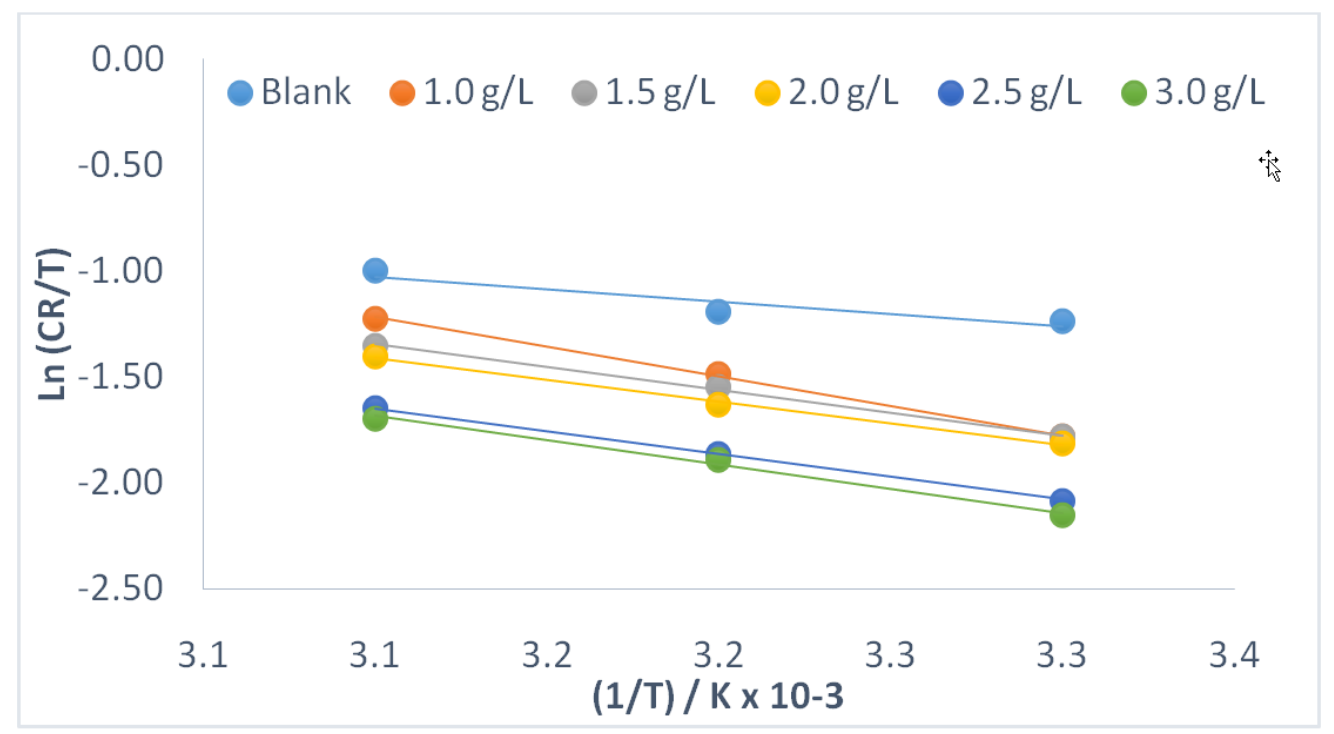

Figure 6. Transition state plots for corrosion of $\mathrm{Cu}-\mathrm{Zn}-\mathrm{Fe}$ alloy in the presence and absence of root-leaves synergy extracts of Solanum melongena leaves. 


\subsection{Adsorption isotherm consideration}

The surface coverage $(\theta)$ values for different concentrations of the inhibitors in $1 \mathrm{M}$ $\mathrm{HCl}$ solutions was evaluated using gasometric data. The data were tested graphically to find a suitable adsorption isotherm to describe the adsorption characteristics of the extracts. A plot of $\log (\theta / C)$ against $\log C$ (Figure 7) showed a straight line with regression coefficient of approximately unity (Table 4) indicating that adsorption followed the Langmuir adsorption isotherm [8, 15, 29-31]. The values for the equilibrium adsorption-desorption constant showed decrease with increasing temperature. This is an indication of good inhibition at lower temperatures hence a physical adsorption process just as indicated in Table 2 [22-23, 31-33]. The Gibbs free energy of adsorption values were negative and less than $20 \mathrm{~kJ} / \mathrm{mol}$ indicating a physical adsorption, inhibitor stability and spontaneity at the forward reaction [31-34].

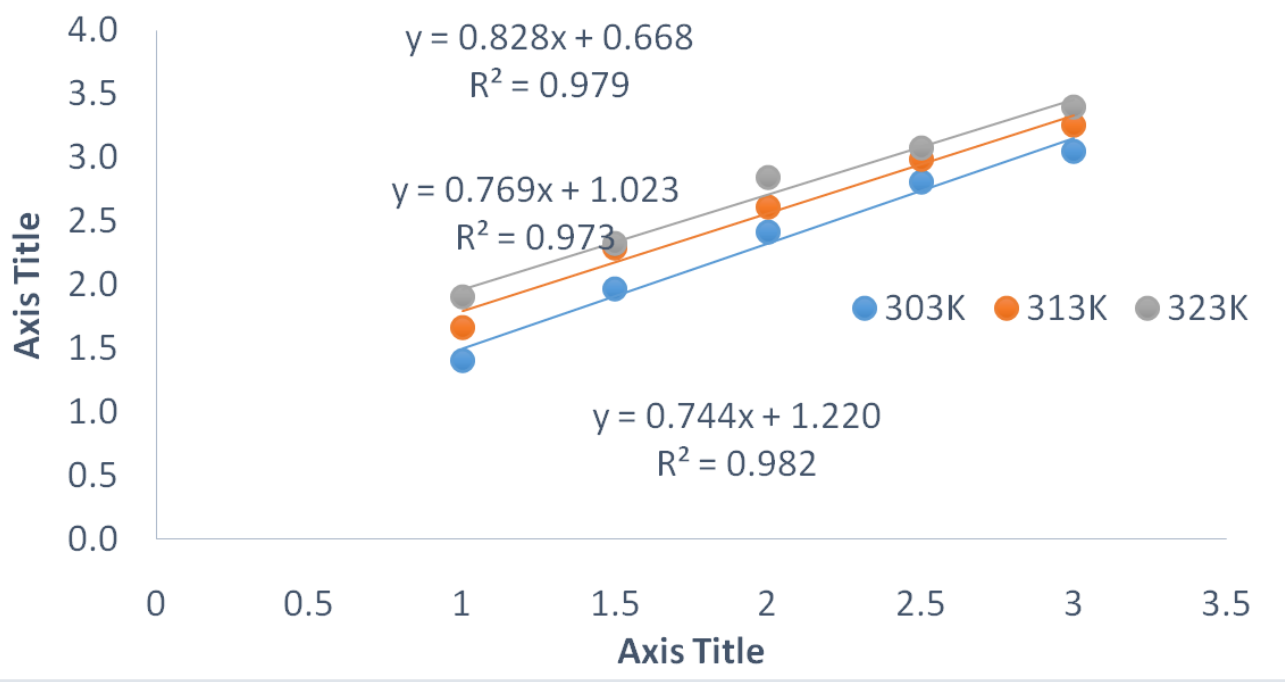

Figure 7. Langmuir adsorption isotherm for corrosion of $\mathrm{Cu}-\mathrm{Zn}-\mathrm{Fe}$ alloy in the presence and absence of root-leaves synergy extracts of Solanum melongena leaves. 
Table 4. Adsorption parameters for corrosion of $\mathrm{Cu}-\mathrm{Zn}-\mathrm{Fe}$ alloy in the presence and absence of root-leaves synergy extracts of Solanum melongena leaves

\begin{tabular}{cccc}
\hline Temp. $(\mathrm{K})$ & $\begin{array}{c}\text { Equil. Const. } \\
k(\mathrm{~g} / \mathrm{L})\end{array}$ & $\begin{array}{c}\text { Corr. Coef. } \\
\left(R^{2}\right)\end{array}$ & $\begin{array}{c}\Delta G_{\text {ads }}^{*} \\
(\mathrm{KJ} / \mathrm{mol})\end{array}$ \\
\hline 303 & 0.8191 & 0.9829 & -444.22 \\
313 & 0.9773 & 0.9737 & -318.40 \\
323 & 1.4959 & 0.9797 & -171.33 \\
\hline
\end{tabular}

\section{Conclusion}

1. The percentage inhibition efficiency obtained from this experiment for corrosion inhibition of $\mathrm{Cu}-\mathrm{Zn}-\mathrm{Fe}$ alloy using synergy of root-leaves extracts of Solanum melongena leaves showed significant inhibition.

2. Inhibition was by adsorption of molecules of the combined extracts on the surface of the $\mathrm{Cu}-\mathrm{Zn}-\mathrm{Fe}$ alloy there by retarding the anodic dissolution and cathodic hydrogen evolution.

3. Adsorption study reveals that the mechanism of adsorption follows Langmuir isotherm which implies a monolayer adsorption calculated from the correlation coefficient of 0.999 approximate.

4. Thermodynamic study reveals an inhibitor that was physical adsorped, endothermic, stabled, spontaneous and with a very insignificant degree of disorderliness

\section{References}

[1] O. Benali, H. Benmehdi, O. Hasnaoui, C. Selles and R. Salghi, Green corrosion inhibitor: inhibitive action of tannin extract of Chamaerops humilis plant for the corrosion of mild steel in 0.5 $\mathrm{M} \mathrm{H}_{2} \mathrm{SO}_{4}$, J. Mater. Environ. Sci. 4(1) (2013), 127-138.

[2] B.R. Fatemeh, M. Saeed and D. Athareh, Corrosion inhibition of mild steel in stimulated cooling water by blends of molybdate, nitrite and picrate as new anodic inhibitor, Anticorrosion Methods \&Materials 59(4) (2012), 182-189.

[3] K. Parameswari, S. Chitra, A. Selvaraj, S. Brindha and M. Menaga, Investigation of benzothiazole derivatives as corrosion inhibitors for mild steel, Port. Electrochim. Acta 30(2) (2012), 89-98. https://doi.org/10.4152/pea.201202089 
[4] C.B. Pradeep Kumar and K.N. Mohana, Adsorption and thermodynamic characteristics of Plumeria rubra plant extracts on mild steel corrosion in industrial water medium, International Research Journal of Pure \& Applied Chemistry 3(4) (2013), 330-346. https://doi.org/10.9734/IRJPAC/2013/5397

[5] R. Saratha and R. Meenakshi, Corrosion inhibitor: A plant extract, Der Pharma. Chemica 2(1) (2010), 287-294.

[6] T. He, W. Emori, R. Zhang, P.C. Okafor, M. Yang and C. Cheng, Detailed characterization of Phellodendron chinense Schneid and its application in the corrosion inhibition of carbon steel in acidic media, Bioelectrochemistry 130 (2019), 107332. https://doi.org/10.1016/j.bioelechem.2019.107332

[7] K. Boumhara, H. Harhar, M. Tabyaoui, A. Bellaouchou, A. Guenbour and A. Zarrouk, Corrosion inhibition of mild steel in $0.5 \mathrm{M} \mathrm{H}_{2} \mathrm{SO}_{4}$ solution by Artemisia herba-alba oil, J. Bio. Tribo. Corros. 5 (2019), Article No. 8. https://doi.org/10.1007/s40735-018-0202-8

[8] H.S. Gadow and M.M. Motawea, Investigation of the corrosion inhibition of carbon steel in hydrochloric acid solution by using ginger roots extract, RSC Advances 7(40) (2017), 24576-24588. https://doi.org/10.1039/C6RA28636D

[9] K.H. Hassan, A.A. Khadom and N.N. Kurshed, Citrus aurantium leaves extracts as sustainable corrosion inhibitor of mild steel in sulfuric acid, South African J. Chemical Engineering 22 (2016), 1-5. https://doi.org/10.1016/j.sajce.2016.07.002

[10] H. Louis, J. Japari, A. Sadia, M. Philip and A. Bamanga, Photochemical screening and corrosion inhibition of Poupartia birrea back extracts as a potential green inhibitor for mild steel in 0.5 M H2SO4 solution, World News Nat. Sci. 10 (2017), 100-112.

[11] V. Vorobyova and M. Skiba, A pricot pomace extract as a natural corrosion inhibitor of mild steel corrosion in $0.5 \mathrm{~m} \mathrm{NaCl}$ solution: a combined experimental and theoretical approach, Journal of Chemical Technology and Metallurgy 55(1) (2015), 210-222.

[12] S.A. Umoren and M.M. Solomon Effect of halide ions on the corrosion inhibition efficiency of different organic species-a review, J. Ind. Eng. Chem. 21 (2015), 100-107. https://doi.org/10.1016/j.jiec.2014.09.033

[13] I.E. Uwah, B.U. Ugi, P.C. Okafor and A.I. Ikeuba, Comparative study of corrosion inhibition and adsorption characteristics of ethanol extracts of Andrographis paniculata (King bitters) and Vernonia amygdalina (Bitter leaf) on Mild Steel in $\mathrm{HCl}$ solution, International Journal of Applied Chemistry 9(1) (2013), 73-88.

[14] C. Sangeetha, Chinnakani and S. Selvaraj, Jatropha gossyfolia - A green inhibitor act as anticorrosive agent on carbon steel, Journal of Advanced Scientific Research 11 (2020), 1 . 
[15] K.A. Salima, B.A. Wassan and A.K. Anees, Synthesis and investigations of heterocyclic compounds as corrosion inhibitors for mild steel in hydrochloric acid, International Journal of Industrial Chemistry 10 (2019), 159-173. https://doi.org/10.1007/s40090-0190181-8

[16] M. AbdallahaI, S.O. Zaafarany, A.A. Al-Karanee, El-Fattaha, Antihypertensive drugs as an inhibitors for corrosion of aluminum and aluminum silicon alloys in aqueous solutions, Arabian Journal of Chemistry 5(2) (2012), 225-234. https://doi.org/10.1016/j.arabjc.2010.08.017

[17] M.T. Majd, M. Ramezanzadeh, B. Ramezanzadeh and G. Bahlakeh, Production of an environmentally stable anti-corrosion film based on Esfand seed extract molecules-metal cations: Integrated experimental and computer modeling approaches, Journal of Hazardous Materials 382 (2020), 1-16. https://doi.org/10.1016/j.jhazmat.2019.121029

[18] N.C. Ngobiri, E.E. Oguzie, Y. Li, L. Liu, N.C. Oforka and O. Akaranta, Eco-friendly corrosion inhibition of pipeline steel using Brassica oleracea, International Journal of Corrosion 2015 (2015), Art. ID 404139. https://doi.org/10.1155/2015/404139

[19] I.H. Ali and M. H.A. Suleiman, Effects of acid extract of leaves of Juniperus procera on corrosion inhibition of carbon steel in $\mathrm{HCl}$ solution, Int. J. Electrochem. Sci. 13 (2012), 3922.

[20] A.S. Fouda, M. Eissa and El-Hossiany, Ciprofloxacin as eco-friendly corrosion inhibitor for carbon steel in hydrochloric acid solution, Int. J. Electrochem. Sci. 13 (2018), 1109611112. https://doi.org/10.20964/2018.11.86

[21] B.M. Prasanna, B.M. Praveen, H. Narayana, T.V. Venkatarangaiah and C.T. Harmesh, Ketosulfone drug as a green corrosion inhibitor for mild steel in acidic medium, Ind. Eng. Chem. Res. 53(20) (2014), 8436-8444. https://doi.org/10.1021/ie500232g

[22] D.A. Al-Shehri, Oil and gas wells: enhanced wellbore casing integrity management through corrosion rate prediction using an augmented intelligent approach, Sustainability 11(8) (2019), 1-18. https://doi.org/10.3390/su11030818

[23] Anees A. Khadom, Baker M. Abod, Hameed B. Mahood and Abdul Amir H. Kadhum, Galvanic corrosion of steel-brass couple in petroleum waste water in presence of a green corrosion inhibitor: electrochemical, kinetics, and mathematical view, Journal of Failure Analysis and Prevention 18 (2018), 1300-1310.

https://doi.org/10.1007/s11668-018-0525-2

[24] P.O. Ameh and N.O. Eddy, Theoretical and experimental studies on the corrosion inhibition potentials of 3-nitrobenzoic acid for mild steel in $0.1 \mathrm{M} \mathrm{H}_{2} \mathrm{SO}_{4}$, Cogent Chemistry 2 (2016), 1253904. 
[25] A.S. Fouda, K. Shalabi and A. E-Hossiany, Moxifloxacin antibiotic as green corrosion inhibitor for carbon steel in $1 \mathrm{M} \mathrm{HCl}$, J. Bio. Tribo. Corros. 2 (2016), Article 18. https://doi.org/10.1007/s40735-016-0048-x

[26] P.O. Ameh and N.O. Eddy, Experimental and computational chemistry studies on the inhibition efficiency of phthalic acid (PHA) for the corrosion of aluminum in hydrochloric and tetraoxosulphate (VI) acids, Protection of Metals and Physical Chemistry of Surfaces (2018), 1-13.

[27] P.R. Ammal, M. Prajila and A. Joseph, Effective inhibition of mild steel corrosion in hydrochloric acid using EBIMOT, a 1,3,4-oxadiazole derivative bearing a 2ethlbenzimidazole moiety: Electro analytical, computational and kinetic studies, Egyptian Journal of Petroleum 27 (2018), 823-833. https://doi.org/10.1016/j.ejpe.2017.12.004

[28] K.F. Khaled and N.A. Al-Mobarak, A predictive model for corrosion inhibition of mild steel by thiophene and its derivatives using artificial neural network, Int. J. Electrochem. Sci. 7 (2012), 1045-1059.

[29] G.A. Cookey, B.L. Tambari and D.S. Iboroma, Evaluation of corrosion inhibition potentials of green tip forest lily (Clivia nobilis) leaves extract on mild steel in acid media, Journal of Applied Sci. Env. Mgt. 22 (1) (2018), 90-94.

https://doi.org/10.4314/jasem.v22i1.16

[30] O. Dagdag, A. El Harfi, O. Cherkaoui, Z. Safi et al., Rheological, electrochemical, surface, DFT and molecular dynamics simulation studies on the anticorrosive properties of new epoxy monomer compound for steel in $1 \mathrm{M} \mathrm{HCl}$ solution, RSC Advances 9 (2019), 4454-4462. https://doi.org/10.1039/C8RA09446B

[31] A. Singh, E.E. Ebenso and M.A. Quraishi, Theoretical and electrochemical studies of Metformin as corrosion inhibitor for mild steel in hydrochloric acid solution, Int. J. Electrochem. Sci. 7 (2012), 4766-4779.

[32] A. Singh, V.K. Singh and M.A. Quraishi, Inhibition effect of environmentally benign Kuchla (Strychnos Nuxvomica) seed extract on corrosion of mild steel in hydrochloric acid solution, Rasayan J. Chem. 3(4) (2010) 811-824.

[33] I.E. Uwah, A.I. Ikeuba, B.U. Ugi and V.M. Udowo, Comparative study of the inhibition effects of alkaloid and non-alkaloid fractions of the ethanolic extracts of Costus afer stem on the corrosion of mild steel in $5 \mathrm{M} \mathrm{HCl}$ solution, Global Journal of Pure \& Applied Sciences 19(1) (2013), 23-31. https://doi.org/10.4314/gjpas.v19i1.4

[34] I.E. Uwah, B.U. Ugi, A.I. Ikeuba and K.E. Etuk, Evaluation of the inhibitive action of eco-friendly benign Costus afer stem extract of mild steel in $5 \mathrm{M} \mathrm{HCl}$ solutions, International Journal of Development \& Sustainability 2(3) (2013), 1970-1981. 